\title{
Assessment on connection between shallow and deep aquifers using isotope analysis of surface water and groundwater in Sunsari and Morang Districts
}

\author{
*Sharmila Neupane ${ }^{1}$, Ananta Prasad Gajurel ${ }^{1}$, Nir Shakya ${ }^{1}$, Maartin Lupker ${ }^{2}$, and Rabina Hada ${ }^{1}$ \\ ${ }^{1}$ Department of Geology, Tri-Chandra Multiple Campus, Kathmandu, Nepal. \\ ${ }^{2}$ ETH-Zurich, Switzerland \\ *Corresponding author: neupanesharmila102@gmail.com
}

\begin{abstract}
The Sunsari and the Morang Districts confine the eastern region of the Koshi River and are considered as a huge potential of groundwater zones. The study mainly focuses on the concept of delineation of recharge source of groundwater and connection between aquifer system through isotopic analysis. Altogether 33 samples are collected from surface and groundwater for the isotopic analysis. Majority of the samples of flowing artesian wells are encountered under the range of $-7.03 \%$ to $-6.53 \%$. The shallow aquifers fall under the range of $-5.94 \%$. to $-5.34 \%$ and deep aquifers fall over a wide range of $-7.13 \%$. to $-6.53 \%$ o for $\delta^{18} \mathrm{O}$. Clustering of samples from isotopic analysis gives idea of surface water and groundwater interconnection along with the recharge source identification. Isotopic variation of majority of samples ranges from $-7.34 \%$ to- $4.74 \%$ while depleted value for $\delta^{18} \mathrm{O}$ is $-10.16 \%$ in shallow aquifer of Jamungachhi, which indicates that the recharge source is precipitation at higher elevation. The d excess (greater than 10\%o) concluded that the aquifer system in the study area is complex and recharged from various sources. The range of enrichment is measured as $2.6 \%{ }_{0}<1.96 \%{ }_{0}<1.87 \%_{0}<1.55 \%$ for shallow aquifers, rivers, deep aquifers and flowing artesian well. The significant increase in coarse particle towards the norther part reveals the good aquifer sequence in the northern zone and proves the best recharge area. The overall aquifer system in the study area is complex and recharged from various sources. Most of the aquifers are recharged from the rivers and precipitation at higher altitude.
\end{abstract}

Keywords: Stable isotopes, Groundwater recharge, Connectivity assessment, Flow path

Paper Received: 24 Jan 2019

Paper Accepted: 31 May 2019

\section{INTRODUCTION}

The Terai Plain that marks the northern fringe of the Into-Gangatic Plain is the major groundwater potential zone in Nepal. The continuous deposition of sediments from the Himalayas makes it more porous hence, exploration of groundwater makes feasible. Understanding of aquifer's recharge process and their linkage with surface water is essential for integrating water resources all over the earth. Several quantitative databases have been developed encountering perspective of the arsenic contamination of water in aquifer of the Terai region, however no study has been undertaken to understand the details of groundwater flow system, recharge source and geochemical approaches in this area. The study mainly focuses on the concept of delineation of recharge source of groundwater through isotopic analysis of surface water and groundwater. To establish the interrelationship between aquifer system through stable isotopes of $\delta^{18} \mathrm{O}$ and $\delta^{2} \mathrm{H}$ plot, $\delta^{18} \mathrm{O}$ and $\delta^{2} \mathrm{H}$ are chosen to trace the groundwater and surface water flow and to identify the recharge source.

Craig (1961) has identified the isotopic contents of Oxygen and Hydrogen are linearly related worldwide, introducing
Global meteoric water line that provide empirical relationship describing precipitation, isotopic content collected worldwide.

Winter et al. (1998), has established the fact that range of topographic, geologic and climatic landscape play significant role to groundwater and surface water interconnection. Groundwater discharge is more in low lying areas where several rivers profoundly dominate their flow regimes with different origin. Jenkins et al. (1987) had conducted, in a study on "A stable isotope reconnaissance of groundwater resources in Kathmandu Valley, Nepal", the isotopic signature, flow regimes, and possible dynamics of the valley from the sample collected from groundwater, surface water spring water and precipitation during monsoon season. Samples were analysed for environmental isotopes Oxygen-18 and Deuterium, and concluded that the stable isotope signatures of the valley groundwater were useful to identify the source and to differentiate between various groundwater flow regimes. Gajurel et al. (2006) published some findings on isotopic composition and its variability with elevation and meteoric water. According to their study, isotopic signature of $\delta^{18} \mathrm{O}$ was around $-18 \%$ o to the north of the High Himalayan range and those up to $-8 \%$ o to $-4 \%$ o in the Indo-Gangatic Plain, while $\delta^{18} \mathrm{O}$ of river were seasonally 


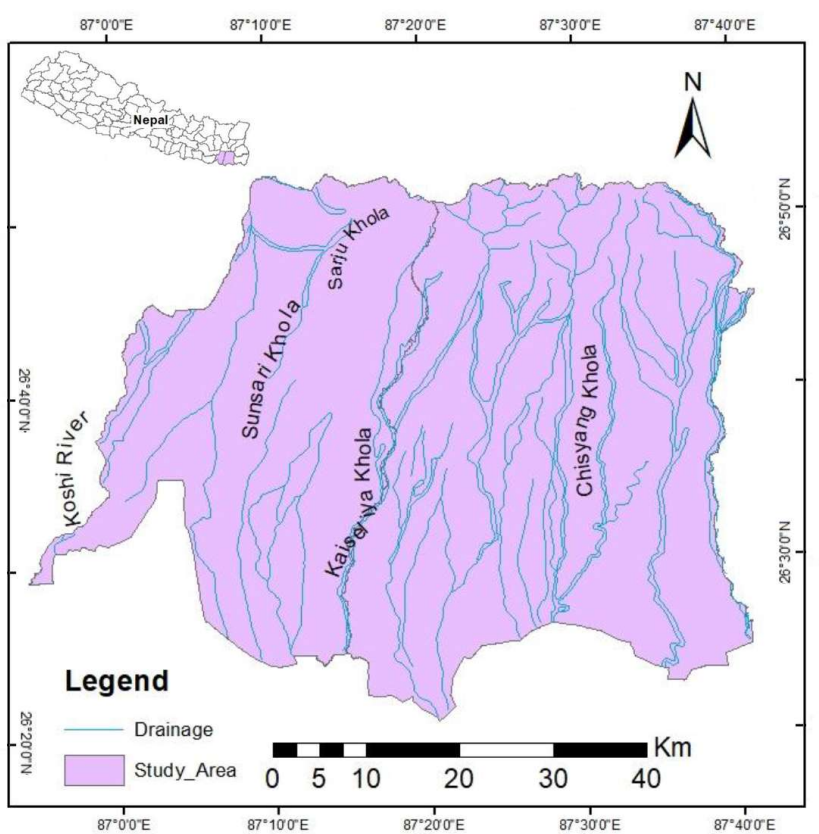

Fig. 1: Location Map of Study Area

variable and monsoon rain could bear $4 \%$ o lower than precipitation during the dry season as were observed. The isotopic variation in the foothill rivers ranged from $-11 \%$ o to $-7 \%$ o for wet and $-8 \%$ o to $-5 \%$ o for dry seasons.

Viava (2015) has documented, for the surface water and groundwater connectivity, that compositional difference of less than $20 \%$ between surface water and groundwater samples would indicate high connectivity, $20 \%$ and $40 \%$ a moderate connectivity; and higher than $40 \%$ to low connectivity condition. These percentages were obtained under comparison I the central rhombus of the piper diagram. Based on the water stable isotopes, the range (difference between the lowest and highest value) of the recorded isotopic signature was determined for both $\delta^{2} \mathrm{H}$ and $\delta^{18} \mathrm{O}$ and same criteria (20\% and $40 \%$ based on range) were considered.

\section{STUDY AREA}

The study area covers two districts of Eastern Development Region, which incorporates the Koshi River basin. The Sunsari and Morang Districts confine the eastern region of the Koshi River and are of huge potential of groundwater zones. The Sunsari District is bounded by the Koshi River in the west and the Morang District in the east. To the west of the Sunsari District, the Morang District is bounded by the Jhapa District in the east. The study area is easily assessed by all means of road transportation through the East-West Highway, and lies in the middle and the southern Terai, where good gravel aquifers can be found at shallow depth. The plain land featured with valley is bordered by several river channels and canals, of which the Koshi River is the major river drained by numerous tributaries: Kaiseliya Khola, Sunsari Khola, Chisyang Khola, Lohandra Khola, Sarju Khola, etc. (Fig. 1).

\section{Sampling and analytical methods}

Altogether 33 samples were collected from surface water and groundwater from different locations (Fig. 2). Special attention was taken to avoid any contamination and effect of exchange with atmosphere while sampling. The sample taken for isotopic analysis was filtered by using filter to avoid any suspended sediments. Before sampling, all bottles were rinsed with sampling water 3 to 4 times for better in-situ sample. To maintain the accuracy, groundwater from shallow and deep tube wells were left for sufficient time, so that the sample represent the groundwater of aquifer.

Stable isotopic ratio of Oxygen and Hydrogen were analysed at ETH lab, Zurich of Switzerland and results were expressed in ä\%o with respect to Vienna Standard Mean Ocean (VSMOW).

\section{RESULTS}

\section{Isotopic Composition}

The analysis of ä18O and $\ddot{2} 2 \mathrm{H}$ is based on the isotopic ratio of the collected sample of surface water and subsurface water. The statistical results are discussed considering $\pm 0.25 \%$ o and $\pm 4 \%$ as the limiting range for $\delta^{18} \mathrm{O}$ and $\delta^{2} \mathrm{H}$.

The range of $\delta^{18} \mathrm{O}$ varies from $-10.16 \%$ to $-4.74 \%$. Highest depletion $(-10.16 \%)$ is noticed in shallow well of Jammungachhi while the highest enrichment is observed ($4.74 \%$ ) in the shallow hand pump of Tankesinwari (Table 1). $\delta^{2} \mathrm{H}$ values range from $-66.36 \%$ to $26.94 \%$ with average of $40.35 \%$. The distribution of isotopic composition of sample is presented in the histogram. The graphical representation shows that the isotopic ratio of $\delta^{18} \mathrm{O}$ has the highest frequency for $5.5 \%$ to $-5 \%$ and that for $\delta^{2} \mathrm{H}$ is $-44 \%$ to $-41 \%$ (Fig. 3).

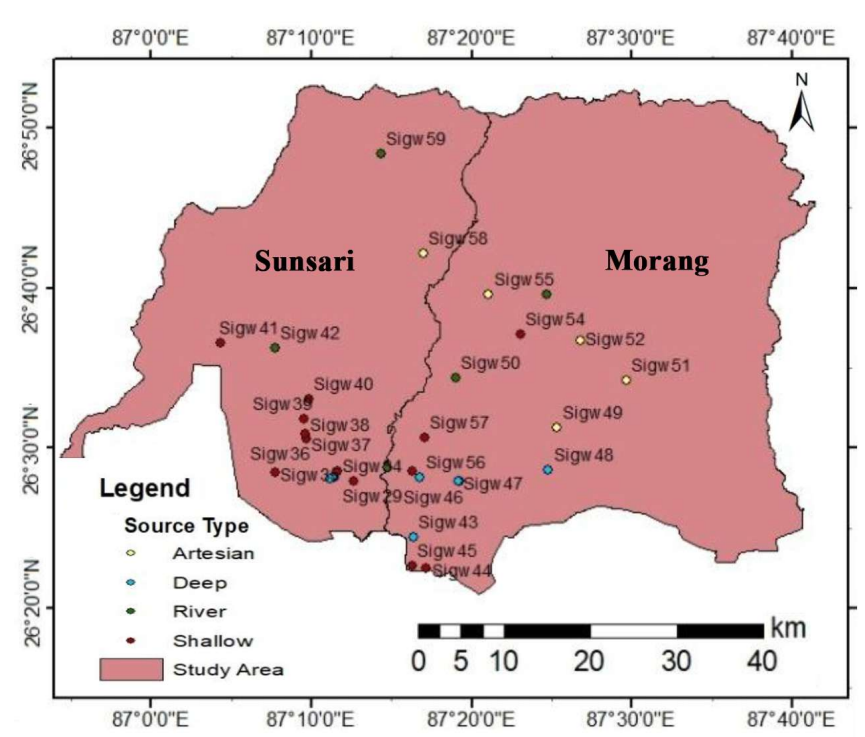

Fig. 2: Sampling Stations 
Table 1: Isotopic ratio of collected sample

\begin{tabular}{|c|c|c|c|c|c|c|c|c|}
\hline Sample ID & Easting & Northing & Elv. (m) & District & Location & $\delta 180(\% 0)$ & $\delta 2 \mathrm{H}(\% 0)$ & $\mathrm{d}$ excess $(\%)$ \\
\hline Sigw27 & 87.27 & 26.48 & 70 & Morang & Jamungachhi & -10.16 & -66.36 & 14.91 \\
\hline Sigw28 & 87.25 & 26.48 & 61 & Sunsari & Ramgunj,Belbachhiya & -5.42 & -33.15 & 10.25 \\
\hline Sigw29 & 87.21 & 26.47 & 62 & Sunsari & Amaibela & -6.72 & -42.19 & 11.60 \\
\hline Sigw30 & 87.19 & 26.47 & 60 & Sunsari & Eastern sugar mill & -7.42 & -47.94 & 11.41 \\
\hline Sigw31 & 87.19 & 26.47 & 59 & Sunsari & Eastern sugar mill & -7.40 & -46.96 & 12.23 \\
\hline Sigw32 & 87.19 & 26.47 & 69 & Sunsari & Eastern sugar mill & -7.34 & -46.79 & 11.90 \\
\hline Sigw33 & 87.19 & 26.47 & " " & Sunsari & Eastern sugar mill & -4.91 & -29.59 & 9.71 \\
\hline Sigw34 & 87.19 & 26.48 & 59 & Sunsari & Amaibela & -5.20 & -31.93 & 9.67 \\
\hline Sigw35 & 87.13 & 26.48 & 71 & Sunsari & Madhyaharsahi & -7.01 & -45.44 & 10.65 \\
\hline Sigw36 & 87.16 & 26.51 & 63 & Sunsari & Rashi & -5.61 & -33.30 & 11.60 \\
\hline Sigw37 & 87.16 & 26.52 & 65 & Sunsari & Satyajhora & -5.79 & -36.28 & 10.04 \\
\hline Sigw38 & 87.16 & 26.52 & 59 & Sunsari & Satyajhora & -5.95 & -37.14 & 10.46 \\
\hline Sigw39 & 87.16 & 26.53 & 101 & Sunsari & Satyajhora & -5.72 & -35.62 & 10.15 \\
\hline Sigw40 & 87.16 & 26.55 & 64 & Sunsari & Hattimoda & -5.65 & -36.59 & 8.59 \\
\hline Sigw41 & 87.07 & 26.61 & 75 & Sunsari & Pachhim Kusaha & -6.94 & -45.35 & 10.20 \\
\hline Sigw42 & 87.13 & 26.60 & 82 & Sunsari & Sunsari Khola & -6.53 & -42.56 & 9.70 \\
\hline Sigw43 & 87.27 & 26.41 & 54 & Morang & Rani & -7.69 & -49.68 & 11.85 \\
\hline Sigw44 & 87.29 & 26.37 & 54 & Morang & Buddhanagar & -5.74 & -35.71 & 10.23 \\
\hline Sigw45 & 87.27 & 26.38 & 56 & Morang & Bhediyari & -5.37 & -33.55 & 9.45 \\
\hline Sigw46 & 87.32 & 26.47 & 59 & Morang & Katahari & -7.06 & -42.61 & 13.89 \\
\hline Sigw47 & 87.32 & 26.47 & 59 & Morang & Katahari & -6.65 & -42.00 & 11.18 \\
\hline Sigw48 & 87.41 & 26.48 & 65 & Morang & Karsiya & -6.97 & -42.18 & 13.61 \\
\hline Sigw49 & 87.42 & 26.52 & 70 & Morang & Babiyabirta & -5.73 & -34.61 & 11.21 \\
\hline Sigw50 & 87.32 & 26.57 & 81 & Morang & Chisan Khola & -5.89 & -37.07 & 10.08 \\
\hline Sigw51 & 87.49 & 26.57 & 84 & Morang & Kerung & -6.82 & -41.82 & 12.77 \\
\hline Sigw52 & 87.45 & 26.61 & 105 & Morang & Dangighat & -7.28 & -44.29 & 13.98 \\
\hline Sigw53 & 87.41 & 26.66 & 134 & Morang & Lohandra Khola & -6.22 & -39.63 & 10.16 \\
\hline Sigw54 & 87.38 & 26.62 & 110 & Morang & Sisaugau Sundarharaicha & -6.72 & -41.16 & 12.56 \\
\hline Sigw55 & 87.35 & 26.66 & 109 & Morang & Gothgau & -6.86 & -42.05 & 12.86 \\
\hline Sigw56 & 87.28 & 26.47 & 57 & Morang & Munalpath & -5.55 & -34.19 & 10.17 \\
\hline Sigw57 & 87.28 & 26.51 & 71 & Morang & Tankeshwori & -4.74 & -26.94 & 11.02 \\
\hline Sigw58 & 87.28 & 26.70 & 125 & Sunsari & NARC, & -6.69 & -40.54 & 12.98 \\
\hline Sigw59 & 87.24 & 26.81 & 234 & Sunsari & Sarjukhola & -7.38 & -46.26 & 12.80 \\
\hline
\end{tabular}
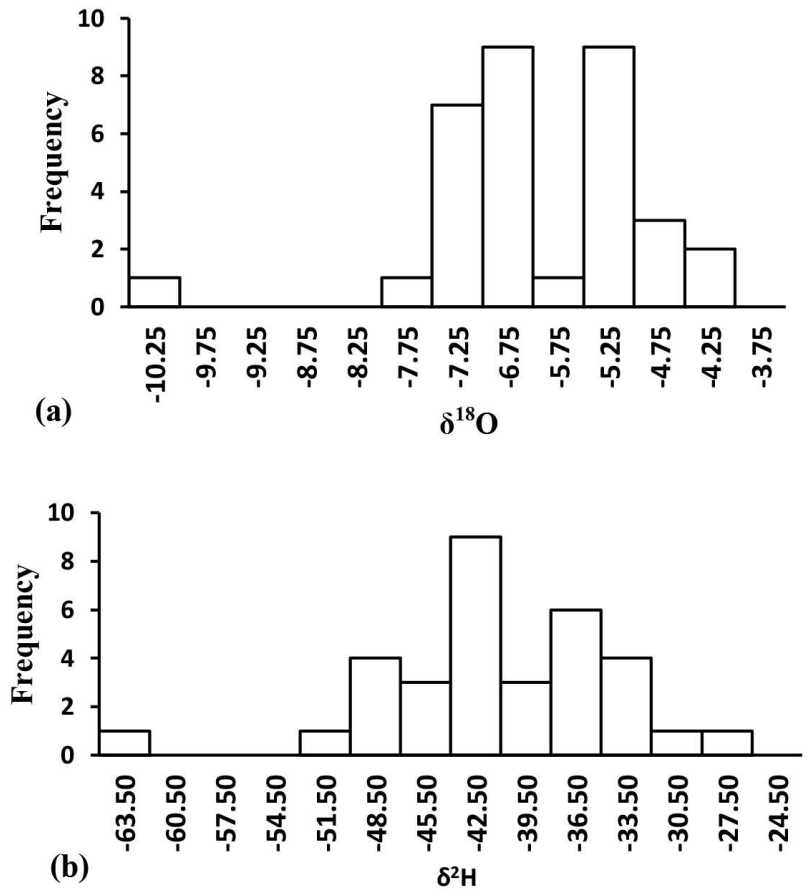

Fig. 3: Histogram (a) $\delta^{18} \mathrm{O}$ (b) $\delta^{2} \mathrm{H}$

\section{Deuterium Excess}

The calculated d excess value (Table 1) varies from $8.59 \%$ in shallow aquifer to $14.91 \%$ in shallow aquifer situated at Jamungachhi. The intercept (d excess) varies from $9.71 \%$ to $13.89 \%$, with average value of $11.76 \%$ or deep aquifer while it varies from $8.59 \%$ to $14.91 \%$ with an average of $10.87 \%$. for shallow aquifer and the value of intercept for the case of artesian well ranges from $11.2 \%$ to $13.28 \%$.

\section{Spatial distribution}

Majority of the samples of flowing artesian wells are encountered under the range of $-7.03 \%$ to $-6.53 \%$. The shallow aquifers fall under the range of $-5.94 \%$.to-5.34\%o and deep aquifers fall over a wide range of $-7.13 \%$.to $-6.53 \%$ for $\delta^{18} \mathrm{O}$ (Fig. 4).

\section{Isotopic characteristics of Surface water and subsurface water}

From the plot of $\delta^{18} \mathrm{O}$ vs. $\delta^{2} \mathrm{H}$, four rivers clustered the samples including shallow and a deep aquifer based on the isotopic signature shown by collected sample (Fig. 5). The clustering is done limiting the range $\pm 0.25 \%$ for $\delta^{18} \mathrm{O}$ to show 


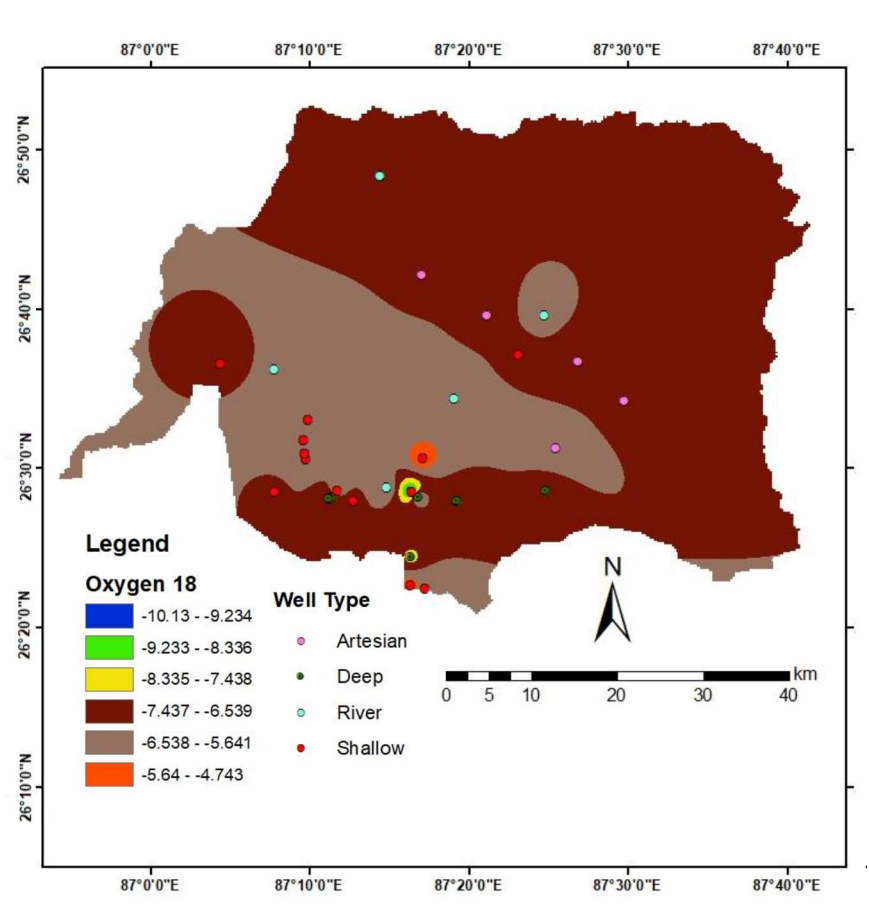

Fig. 4: Spatial Distribution of $\delta^{18} \mathrm{O}$

the connectivity between surface water and groundwater. Among four clusters shown in Fig. 5, the Chisyang Khola (sigw 50) with isotopic composition $-5.89 \%$ for $\delta^{18} \mathrm{O}$ consisted 6 samples of five shallow and a flowing artesian well. The shallow aquifers have $-5.65 \%,-5.72 \%$, $-5.74 \%$ and $-5.95 \%$, and the flowing artesian well has $-5.79 \%$ to $-5.73 \%$. The Kaiseliya Khola has isotopic ratio $-5.42 \%$ : with 3 shallow aquifers with isotopic ratio $-5.20 \%,-5.61 \%$ and $-5.37 \%$, and a deep aquifer with

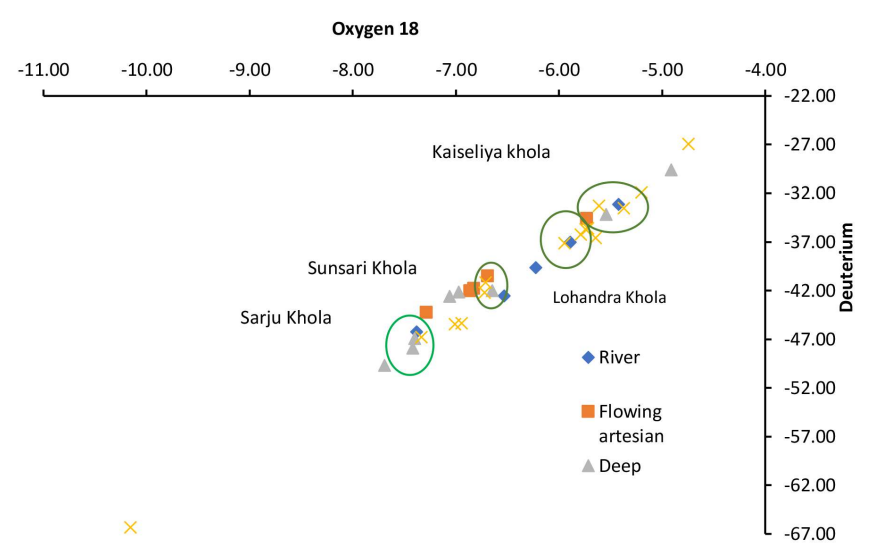

Fig. 5: Isotopic Composition in Surface water and Groundwater

isotopic composition of $-5.55 \%$. The Sunsari Khola whose isotopic ratio is $-6.53 \%$ consisted the sample of shallow aquifers with isotopic ratio $-6.72 \%$, deep aquifer of isotopic ratio $6.65 \%$ and flowing artesian well with isotopic composition $6.69 \%$. Likewise, the Sarju Khola that shows the isotopic ratio $-7.38 \%$ is clustered with two deep aquifers with isotopic ratio $-7.40 \%$ and $-7.42 \%$, a shallow aquifer with isotopic ratio$7.34 \%$ and a flowing artesian well with composition $-7.28 \%$. The Lohandra Khola doesn't group any other aquifer.

\section{Subsurface geology}

Thirteen lithologs were considered to make a 3-D correlation (Fig. 3; Table 2). Gravel type materials are abundant in the northern parts and degradation of coarse particle in the southern part occurs (Fig. 6). This imply that the river originating at the higher altitude and presence of porous materials at the

Table 2: Location of representative lithologs

\begin{tabular}{lllllll}
\hline Location & District & $\mathrm{X}$ & $\mathrm{Y}$ & Altitude $(\mathrm{m})$ & Total Depth $(\mathrm{m})$ & Aquifer materials \\
\hline Tarahara & Sunsari & 528125 & 2953375 & 145 & 44.5 & Gravel and pebble \\
Inarwa & Sunsari & 515125 & 2943625 & 83.1 & 50.9 & Gravel Sandy \\
Lauki & Sunsari & 506500 & 2941875 & 80.5 & 36.9 & sand and Gravel \\
Satyajhoda & Sunsari & 516000 & 2936375 & 77.3 & 16.8 & sand and Gravel \\
Amahibela & Sunsari & 518125 & 2927750 & 69.8 & 24.4 & Sand \\
Shankarpur & Morang & 528125 & 2928125 & 70.2 & 126.2 & Gravel and Sand \\
Biratnagar Hospital & Morang & 528375 & 2928250 & 72.95 & 75.9 & Garvel with Sand \\
Salakpur & Morang & 535125 & 2949250 & 135.5 & 36 & Gravel fine angular \\
Karsiya & Morang & 541563 & 2926375 & 67 & 36.6 & Sand fine to Coarse \\
Karoon & Morang & 548500 & 2938563 & 93 & 30.5 & Sand and Gravel \\
Tankesinuwari & Morang & 527875 & 2934000 & 82.5 & 102.4 & Gravel \\
PTC. Biratnagar & Morang & 526250 & 2922250 & 68 & 92 & Gravel and Sand \\
Dangihat & Morang & 544375 & 2943500 & 107 & 128.2 & Sand and Gravel \\
Indrapur & Morang & 540875 & 2951125 & 141.6 & 123.1 & Gravel \\
\hline
\end{tabular}




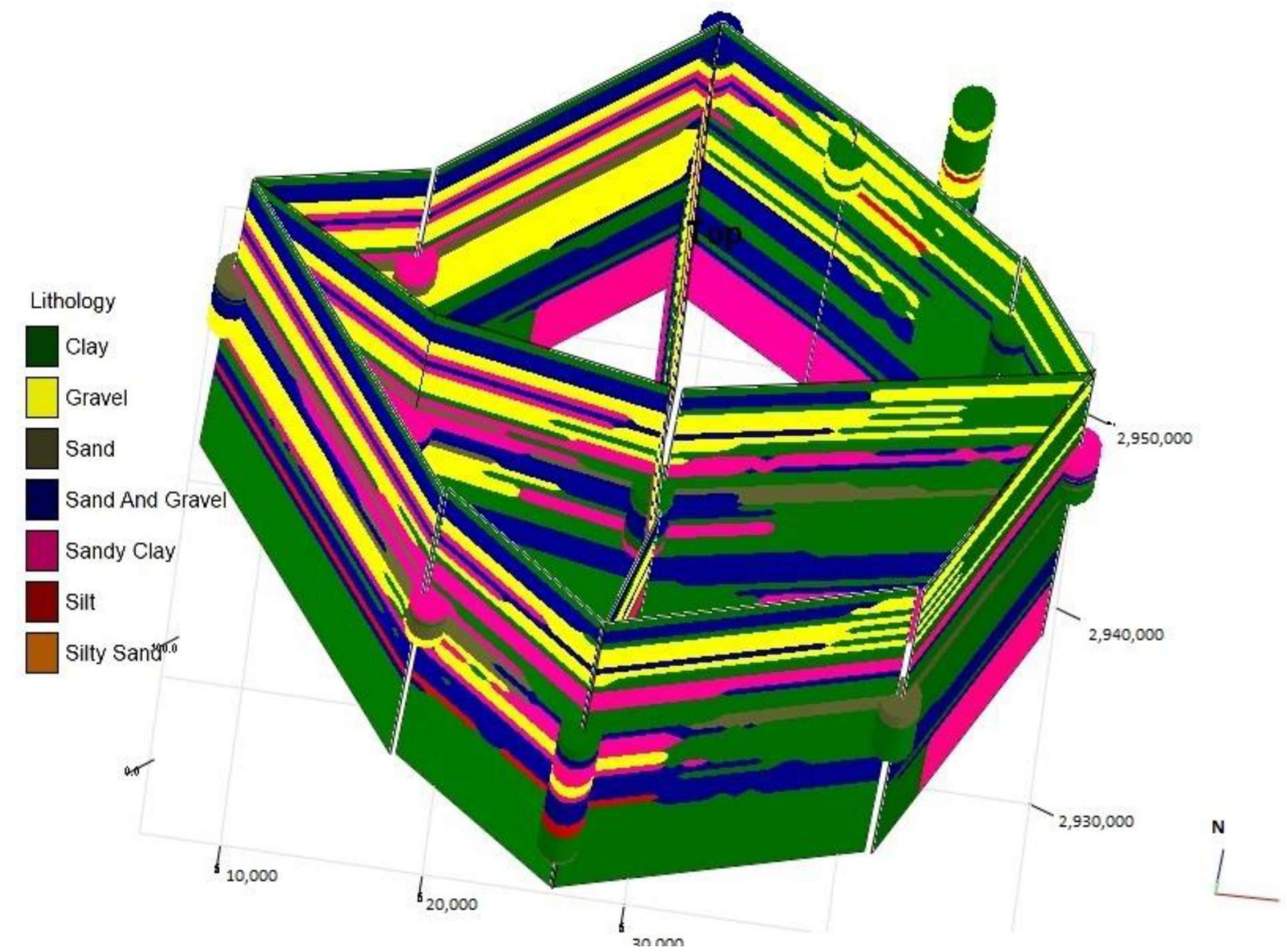

Fig. 6: 3-D subsurface correlation of lithology from logs

northern fringe has major role for the availability of groundwater in study area (Winter et al., 1998).

\section{DISCUSSIONS}

The connectivity between the aquifer system in the study area is primarily based on the isotopic composition of the collected sample. The sample that falls under the same range in isotopic composition are correlated to establish the connectivity between the surface water and groundwater (Fig. 5). The Chisyang Khola (sigw50) shows the connectivity with the shallow aquifer of Satyajhoda (sigw37 and sigw39), Hattimoda (sigw40), Buddhanagar (sigw44) and flowing artesian well of Babiyabirta (sigw49). Similarly, the Sunsari Khola establishes the connectivity with shallow aquifer at Amahibela (sigw29), sisgaun (sigw54), deep aquifer at Tankisinwari (sigw57) and flowing artesian well of National Agriculture and Research Center (sigw58). The Kaiseliya Khola (sigw28) shows the same range of isotopic ratio with shallow aquifer at Amahibela (sigw34), Bhediyari (sigw45), Rashi (sigw36) and deep aquifer at Munalpath (sigw56). The Sarju Khola (sigw59) exhibits the connection with shallow aquifer (sigw32) and deep aquifer (sigw30 and sigw31) of eastern sugar mill, Amahibela at the southern zone.
The interconnection established by isotopic analysis of shallow and deep aquifers in the study area implies that the groundwater system in the area is recharged by major and minor river system. The range of enrichment is measured as $2.6 \%<$ $1.96 \%_{0}<1.87 \%_{0}<1.55 \%$ for shallow aquifers, rivers, deep aquifers and flowing artesian well also established the interconnections between surface water and sub-surface water. Hence on the basis of water stable isotopes, the range (difference between the lowest and highest value) of the recorded isotopic signature was determined for both $\delta^{2} \mathrm{H}$ and $\delta^{18} \mathrm{O}$ and same criteria $(20 \%$ and $40 \%$ based on range) indicate the highest connectivity (Viava, 2015).

The enriched value of isotopic ratio $\left(\delta^{18} \mathrm{O}-4.74 \%\right.$ to $6.74 \%$ ) shows that the majority of the shallow and deep aquifers are recharged from the local rivers distributed in the area as, the isotopic signature of $\delta^{18} \mathrm{O}$ in groundwater showed that the shallow and deep aquifer fall along the same range. Jamungachhi (sigw27) with isotopic ratio ä18O (-10.16\%) indicates depleted recharge source like precipitation at higher altitude (Trinid et al., 2017).

The slope greater than 8 in all samples implies less or no evaporation effect (Clark and Firtz, 1997) and intercept (dexcess) value greater than $10 \%$ in most of the samples suggests 
that the probable input to the recharge is recycling water vapor contributed by the possible surface flows (Fynn, 2016). The wide variation in isotopic signature (ä18O: $-10.16 \%$ o to $-4.74 \%$ ) might be the reflection of multiple recharge source (Keesari et al., 2017). Dominance of coarse particles increasing towards the northern part reveals the good aquifer sequence in the northern zone and hence proves the best recharge area.

\section{CONCLUSION}

Lithological analysis of shallow and deep aquifers from the representative data indicates material at shallow zone with high potential of groundwater exploration. The groundwater and surface water in the study area show the high connectivity on the basis of isotopic signature and its range. The isotopic signature of the collected sample determines the major and minor rivers as recharge source of the groundwater system in the study area. The overall aquifer system in the study area is complex and recharged from various sources. Most of the aquifers are recharged from the rivers and precipitation at higher altitude.

\section{REFERENCES}

Clark, L.D. and Fritz, P., 1997, Environmental isotopes in hydrogeology. New York: Lewis publishers.

Criag, H., 1961, Isotopic Variation in Meteoric water. Science, v. 133(3465), pp. 1702-1703.

Cypaitë, V., 2015, Determination of groundwater flow in SW Iceland with environmental tracers (Rep.). Faculty of
Earth Sciences University of Iceland.

Jenkins, D.T., Sharma, C.K., and Hassett, J.M., 1987, A stable isotope reconnaissance of groundwater resources in the Kathmandu Valley, Nepal. International Atomic Energy Agency (IAEA): IAEA.

Dansgaard,W., 1964, Stable Isotopes in Precipitations Tellus, v. 16 , pp. $436-468$.

Fynn, O.F., Yidana, S.M., Chegbeleh, L.P., and Yiran, G.B., 2016, Evaluating groundwater recharge processes using stable isotope signatures- The Nabogo catchment of the White Volta, Ghana. Arab, Geosci, v. 9, 279p.

Gajurel, A.P., Lanord, C.F., Huyghe, P., Guilmette, C., and Gurung, D., 2006, C and O isotope compositions of modern fresh-water mollusc shells and river waters from the Himalaya and Ganga plain. Chemical Geology, v. 233(1-2), pp. 156-183.

doi: 10.1016/j.chemgeo.2006.03.0028.

Keesari,T., Sharma, D.A., Rishi, M. S., Pant, D., Mohokar, H. V., Jaryal, A.K., and Sinha, U., 2017, Isotope investigation on groundwater recharge and dynamics in shallow and deep alluvial aquifers of southwest Punjab. Applied Radiation and Isotopes, v. 129, pp. 163-170. doi:10.1016/j.apradiso.2017.07.022.

Trinidad, J.G., Guerrero, A.P., Ferreira, H.J., Capetillo, C.B., and Antonio, A.H., 2017, Identifying Groundwater Recharge Sites through Environmental Stable Isotopes in an Alluvial Aquifer. Water 9:8, 569p. 